\title{
Mild Type II Diabetes Markedly Increases Glucose Cycling in the Postabsorptive State and during Glucose Infusion Irrespective of Obesity
}

\author{
Suad Efendic, Sven Karlander, and Mladen Vranic* \\ Department of Endocrinology, Karolinska Hospital, Stockholm, Sweden; and *Departments of Physiology and Medicine, \\ University of Toronto, Toronto, Canada
}

\begin{abstract}
Glucose cycling (GC; G $\rightleftarrows$ G6P) equals $14 \%$ of glucose production in postabsorptive man. Our aim was to determine glucose cycling in six lean and six overweight mild type II diabetics (fasting glycemia: $139 \pm 10$ and $152 \pm 7 \mathrm{mg} / \mathrm{dl}$ ), in postabsorptive state (PA) and during glucose infusion ( $2 \mathrm{mg} / \mathrm{kg}$ per $\mathrm{min}$ ). 14 control subjects were weight and age matched. GC is a function of the enzyme that catalyzes the reaction opposite the net flux and is the difference between hepatic total glucose output (HTGO) (2- $\left.{ }^{3} \mathrm{H}\right]$ glucose) and hepatic glucose production (HGP) (6- $\left.\left.\right|^{3} \mathrm{H}\right]-$ glucose). Postabsorptively, GC is a function of glucokinase. With glucose infusion the flux is reversed (net glucose uptake), and GC is a function of glucose 6-phosphatase. In PA, GC was increased by $100 \%$ in lean (from $0.25 \pm 0.07$ to $0.43 \pm .08 \mathrm{mg} / \mathrm{kg}$ per $\mathrm{min}$ ) and obese (from $0.22 \pm 0.05$ to $0.50 \pm 0.07)$ diabetics. HGP and HTGO increased in lean and obese diabetics by 41 and 33\%. Glucose infusion suppressed apparent phosphatase activity and gluconeogenesis much less in diabetics than controls, resulting in marked enhancement (400\%) in HTGO and HGP, GC remained increased by $100 \%$. Although the absolute responses of C-peptide and insulin were comparable to those of control subjects, they were inappropriate for hyperglycemia. Peripheral insulin resistance relates to decreased metabolic glucose clearance (MCR) and inadequate increase of uptake during glucose infusion. We conclude that increases in HGP and HTGO and a decrease of MCR are characteristic features of mild type II diabetes and are more pronounced during glucose infusion. There is also an increase in hepatic GC, a stopgap that controls changes from glucose production to uptake. Postabsorptively, this limits the increase of HGP and glycemia. In contrast, during glucose infusion, increased GC decreases hepatic glucose uptake and thus contributes to hyperglycemia. Obesity per se did not affect GC. An increase in glucose cycling and turnover indicate hepatic insulin resistance that is observed in addition to peripheral resistance. It is hypothesized that in pathogenesis of type II diabetes, augmented activity of glucose-6-phosphatase and kinase may be of importance.
\end{abstract}

\section{Introduction}

In the liver, substrate cycles may be operative at the three nonequilibrium reactions of glucose metabolism: glucose cycle

Received for publication 24 April 1987 and in revised form 22 September 1987.

J. Clin. Invest.

(c) The American Society for Clinical Investigation, Inc 0021-9738/88/06/1953/09 \$2.00

Volume 81, June 1988, 1953-1961 (glucose $\rightleftharpoons$ glucose-6-phosphate), fructose-6-phosphate cycle (fructose-6-phosphate $\rightleftharpoons$ fructose-1,6-diphosphate), and phosphoenol pyruvate cycle (pyruvate $\rightleftharpoons$ phosphoenol pyruvate). It appears that the most active of these is the first, namely the glucose cycle. By using a combination of glucose labeled in various positions, glucose cycling was detected in normal dogs (1-3), ponies (4), mice (5), rabbits (6), chickens (7), rats (8), and man $(9,10)$.

The rate of substrate cycling is determined by the enzyme that catalyzes a nonequilibrium reaction in the direction opposite to that of the pathway. Hence, in the postabsorptive state the glucose cycle (GC) ${ }^{1}$ is a function of the enzyme glucokinase and is measured as the difference between glucose turnover rates determined by $2-\left[{ }^{3} \mathrm{H}\right]-$ and $6-\left[{ }^{3} \mathrm{H}\right]$ glucose (Fig. 1 $A$ ). This procedure is used with the assumption that the first label is removed at an early stage in the glycolytic pathway (isomerase reaction) while the second is preserved throughout the glycolytic pathway. Hepatic total glucose output (HTGO) is measured by $2-\left[{ }^{3} \mathrm{H}\right]$ glucose and is a function of glucose-6phosphatase, while $6-\left[{ }^{3} \mathrm{H}\right]$ glucose measures hepatic glucose production (HGP) (Fig. $1 \mathrm{~A}$ ). The glucose cycle was also measured by using the difference between $2-\left[{ }^{3} \mathrm{H}\right]-$ and $3-\left[{ }^{3} \mathrm{H}\right]-$ glucose as labels. This is valid, however, only if the rate of the second cycle is marginal, since $3-\left[{ }^{3} \mathrm{H}\right]$ glucose is detritiated in the glycolytic pathway immediately after the second cycle. Therefore, in normal postabsorptive man where the second substrate cycle may be active, the glucose cycle can be precisely measured only by using the difference between $2-\left[{ }^{3} \mathrm{H}\right]-$ and $6-\left[{ }^{3} \mathrm{H}\right]$ glucose (9). The glucose cycle is increased in depancreatized and alloxan-diabetic dogs (models of type I diabetes [3, 11]). In mild lean type II diabetics, glucose cycling was measured using $2-\left[{ }^{3} \mathrm{H}\right]$ and $3-\left[{ }^{3} \mathrm{H}\right]$ glucose, and it amounted to $14 \%$ of glucose production (12). An increased glucose cycle was noted in acromegalic patients despite the fact that they were normoglycemic (13).

During glucose infusions the direction of the metabolic flux changes from net glucose production to net glucose uptake. Under these conditions glucose-6-phosphatase and not glucokinase catalyzes the metabolic reaction that is opposite to the glucose flux. Therefore, GC is a function of the phosphatase activity. This enzyme activity also determines HTGO, which is measured with $2-\left[{ }^{3} \mathrm{H}\right]$ glucose (Fig. $1 \mathrm{~B}$ ). HTGO includes GC plus glucose originating from gluconeogenesis and glycogenolysis. During glucose infusion the component from glycogenolysis is presumably negligible.

1. Abbreviations used in this paper: CV, coefficient of variation; GC, glucose cycling; HGP, hepatic glucose production; HTGO, hepatic total glucose output; MCR, metabolic clearance rate; PA, postabsorptive state. 


\section{A. POSTABSORPTIVE STATE}

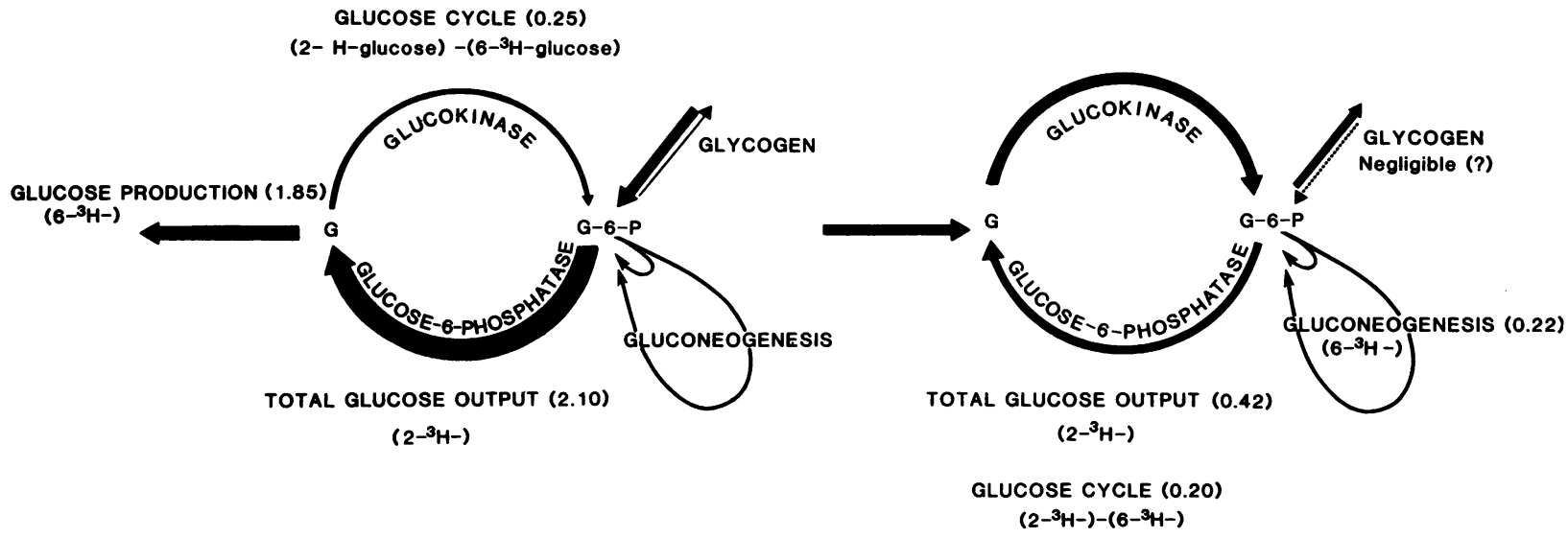

Figure 1. (A) Glucose cycle and turnover ( $\mathrm{mg} / \mathrm{kg}$ per $\mathrm{min}$ ) in normal subjects. During the postabsorptive state, glucose flux equals the glucose production rate and the glucose cycle is a function of the activity of glucokinase. $(B)$ During glucose infusion, glucose flux is reversed and there is net glucose uptake by the liver, and the glucose cycle is a function of glucose-6-phosphatase.

The aim of the present study was to measure the rate of GC in obese and lean type-II diabetes and in matched controls. $2-\left[{ }^{3} \mathrm{H}\right]$ and $6-\left[{ }^{3} \mathrm{H}\right]$ glucose were used as tracers. Glucose cycling was measured in the postabsorptive state (function of glucokinase activity) and during glucose infusion (function of glucose-6-phosphatase activity). Thus, the input of diabetes and obesity on the GC was probed under both metabolic conditions. In addition to GC our studies included measurements of glucose production and utilization. It should be noted that conventional tracer methods measure the overall glucose disposal while $G C$ represents a probe that is specific to liver metabolism.

\section{Methods}

Subjects. The study comprised four groups of participants, as summarized in Table I. All diabetics had an elevated fasting plasma glucose on several occasions. In all controls, fasting plasma glucose and the oral glucose tolerance test was normal according to our criteria (14). The data of the lean controls are derived from a previously published study (13). However, all the experiments included in the present study were performed concurrently and during an 18-mo period.

The slightly higher mean age and lower relative body weight in both diabetic groups compared to the respective control was not significant.
In order to complete the experiments during a reasonable period of time, and since it is difficult to recruit subjects for tracer studies, we have included all available volunteers and patients irrespective of sex. This has resulted in a sex difference between controls and diabetics, especially in overweight groups. The analysis of data in normal weight groups, however, indicates that the turnover results are not related to the sex of the subjects. The following values for hepatic glucose production $(\mathrm{mg} / \mathrm{kg}$ per $\mathrm{min})$ were measured: control males $(1.70,1.83,1.84$, $1.85,1.90)$; control females $(1.81,1.83,1.95)$; diabetic males $(2.57$, $1.95,1.88,1.90)$; and diabetic females $(2.63,2.88)$.

Except for diabetes in the patients, all participants were in good general health and none were taking any medication. The diabetics were prescribed a controlled diet, containing about $45 \%$ carbohydrate. The controls were eating an ordinary Swedish diet with approximately the same proportions of carbohydrate and fat. The experimental protocol was reviewed and approved by the Ethical Committee of the Karolinska Hospital.

Infusions. All subjects were studied in the recumbent position at 8 a.m. after a 12-14-h overnight fast. An indwelling catheter was placed in a cubital vein of each arm, one for infusion of unlabeled and isotopically labeled glucose and the other for blood sampling.

After cannulation, a primed constant infusion of sterile and nonpyrogenic $2-\left[{ }^{3} \mathrm{H}\right]$ and $6-\left[{ }^{3} \mathrm{H}\right]$ glucose (New England Nuclear, Boston, MA) in isotonic saline was started to be continued throughout the experiment ( $240 \mathrm{~min})$. The priming amount of labeled glucose was

Table I. Clinical Data for the Control Subjects and Those with Mild Diabetes

\begin{tabular}{|c|c|c|c|c|c|c|}
\hline \multirow[b]{2}{*}{ Subjects } & \multirow[b]{2}{*}{$\mathbf{n}$} & \multirow{2}{*}{$\frac{\text { Sex ratio }}{M / F}$} & \multirow[b]{2}{*}{ Age } & \multirow[b]{2}{*}{ Body weight } & \multirow{2}{*}{\multicolumn{2}{|c|}{ Fasting plasma glucose }} \\
\hline & & & & & & \\
\hline & & & $y r$ & \% of ideal ${ }^{*}$ & $m M$ & $m g / d l$ \\
\hline \multicolumn{7}{|c|}{ Normal weight } \\
\hline Controls & 8 & $5 / 3$ & $43.8 \pm 2.3^{*}$ & $95 \pm 4$ & $5.0 \pm 0.6$ & $90 \pm 7$ \\
\hline Diabetics & 6 & $4 / 2$ & $49.3 \pm 4.1$ & $83 \pm 3$ & $7.7 \pm 0.5$ & $139 \pm 10$ \\
\hline \multicolumn{7}{|l|}{ Overweight } \\
\hline Controls & 6 & $0 / 6$ & $49.0 \pm 2.0$ & $135 \pm 5$ & $5.5 \pm 0.2$ & $99 \pm 3$ \\
\hline Diabetics & 6 & $6 / 0$ & $53.0 \pm 2.9$ & $121 \pm 1$ & $8.4 \pm 0.4$ & $152 \pm 7$ \\
\hline
\end{tabular}

* Mean+SEM, ${ }^{\ddagger}$ Metropolitan Life Insurance Tables, 1959. Eight lean controls have been included from our previous study (13). 
24-30 $\mu \mathrm{Ci}\left(1 \mathrm{Ci}=3.7 \times 10^{10}\right.$ bequerels $)$ and the infusion rate was $0.20-0.25 \mu \mathrm{Ci} / \mathrm{min}$. After an equilibration period an infusion of unlabeled glucose was started. It was given for an additional 120 min at 2 $\mathrm{mg} / \mathrm{kg}$ per min by means of a Tecmar pump (Medical Market, Sweden). The concentration of glucose in the infusate was measured in each experiment together with the same assay as the plasma samples.

Blood sampling. During the 120 -min equilibration period, blood samples were drawn at $0,90,100,110$, and $120 \mathrm{~min}$. At the start of the infusion of unlabeled glucose the clock was reset to zero and samples were drawn every 10 min during the experiment.

Analytical procedures. Heparinized blood was kept on ice until centrifuged at $4^{\circ} \mathrm{C}$. A plasma sample was used for determination of plasma glucose in triplicate. The rest was frozen at $-20^{\circ} \mathrm{C}$ for later analysis of C-peptide, insulin, glucagon and specific activity of glucose. Plasma glucose was determined by the glucose oxidase method (15). C-peptide was measured by radioimmunoassay with a commercially available kit (Novo Research, Bagsvaerd, Denmark). Insulin was measured by radioimmunoassay using antibodies raised in guinea pigs against porcine insulin. Human insulin served as a standard (16). Blood samples for analysis of glucagon were collected in prechilled tubes containing Trasylol and EDTA. The radioimmunoassay was based on the method of Faloona and Unger and used the $30 \mathrm{~K}$ antibody (17).

Tracer methods and calculations. Measurements of specific activity of glucose were performed after deproteinization with $\mathrm{Ba}(\mathrm{OH})_{2}$ and $\mathrm{ZnSO}_{4}$. The supernatant was passed through anion and cation exchange chromatography (AG 2-X8 and AG 50 W-X8; Bio-Rad Laboratories, Richmond, CA) to remove labeled metabolites from glucose metabolism. An aliquot of the eluate was evaporated to dryness under reduced pressure at $40^{\circ} \mathrm{C}$. After addition of water and liquid scintillation solution the total radioactivity from $2-\left[{ }^{3} \mathrm{H}\right]-$ and $6-\left[{ }^{3} \mathrm{H}\right]$ glucose was measured in a beta scintillation counter. An external standard was used for quenching. All samples and standards were counted for $\mathbf{5 0}$ min and the counts for the samples were at least four times higher than for the background.

The radioactivity of $6-\left[{ }^{3} \mathrm{H}\right]$ glucose was determined as described by Dunn et al. (18). In short, $10.0 \mathrm{mg}$ of glucose was added as a carrier to 2 $\mathrm{ml}$ of the eluate from ion-exchange chromatography. Glucose was then oxidized with periodate to 5 molecules of formic acid (derived from carbons 1-5) and 1 molecule of formaldehyde, derived from carbon 6. After addition of dimedon, formaldehyde precipitates as formaldemethone. The radioactivity of the precipitate was determined after filtering, drying, and weighing. In the four groups studied, the percent recovery for $6-\left[{ }^{3} \mathrm{H}\right]$ glucose by the dimedon procedure was almost identical: normal weight controls $91 \pm 1$ (86-97), normal weight diabetics $88 \pm 2(82-94)$, obese controls $87 \pm 4(80-92)$, obese diabetics $90 \pm 1$ (88-94). This suggests that the calibration of a critical experimental measurement was consistent throughout the study. The radioactivity of $2-\left[{ }^{3} \mathrm{H}\right] \mathrm{glucose}$ was calculated as the difference between total radioactivity and that of $6-\left[{ }^{3} \mathrm{H}\right]$ glucose as measured with the dimedon procedure. Aliquots of the infused mixture of $2-\left[{ }^{3} \mathrm{H}\right]$ and $6-\left[{ }^{3} \mathrm{H}\right]$ glucose were run along with the plasma samples to verify the concentrations of the two labels in the infusate and to estimate possible losses of $6-\left[{ }^{3} \mathrm{H}\right]-$ glucose relative to $2-\left[{ }^{3} \mathrm{H}\right]$ glucose during the dimedon procedure. On the average, $6-\left[{ }^{3} \mathrm{H}\right]$ glucose accounted for $50 \%$ of total radioactivity in the infusate in patients and controls. Aliquots of $2-\left[{ }^{3} \mathrm{H}\right]$ glucose did not display any radioactivity above background after being passed through the dimedon procedure.

At the end of the equilibration period HGP and HTGO $\left(R_{\mathrm{a}}\right.$, rate of appearance) was calculated as the rate of tracer infusion $\left(R_{\mathrm{a}}^{*}\right)$ divided by the specific activity of glucose, or $R_{\mathrm{a}}=R_{\mathrm{a}}^{*} / \mathrm{sp}$ act. During the glucose infusion, $R_{\mathrm{a}}$ and $R_{\mathrm{d}}$ (rate of disappearance) were determined by a method based on a modified single-compartment analysis of glucose turnover (19). It is assumed that rapid changes in the specific activity and concentration of glucose do not occur uniformly within the entire glucose pool. To compensate for this non-uniform mixing, a term of the non-steady state equation was multiplied by a correction factor (pool fraction) of $0.65(20,21)$. This approach for calculating non- steady state kinetics of glucose turnover was validated in vivo (21). A sliding fit technique employing three consecutive values of glucose concentration and specific activity was also used in the calculations as described previously (22). Since very rapid changes in activity occur immediately after the start of the glucose infusion, the first non-steady state $R_{\mathrm{a}}$ value was calculated at 20 min using specific activities at 10 , 20 , and $30 \mathrm{~min}$.

During glucose infusion the HGP and HTGO were calculated by subtracting the rate of infusion of exogenous glucose from the tracerdetermined total rate of glucose appearance. An integrated value of $R_{a}$ during the glucose infusion was calculated as the area under the $R_{\mathrm{a}}$ curve between 20 and $110 \mathrm{~min}$. This value was divided by 90 to obtain the average value during this 90 -min period. In order to obtain mean data reflecting the final part of the experiment, the average Ra during 90-110 min was also calculated. Using the same technique the average Rd was obtained for both time periods during the glucose infusion. The glucose metabolic clearance rate (MCR) was calculated as $R_{\mathrm{d}} / C$, where $C$ is glucose concentration.

The rate of glucose cycling is determined by the activity of the enzyme that catalyzes the flux that is opposite to the net flux of the pathway (23). Taking into account the assumptions listed in the discussion, GC in the postabsorptive state is determined as the difference between hepatic total glucose output $\left(2-\left[{ }^{3} \mathrm{H}\right]\right.$ glucose $)$ and hepatic glucose production $\left(6-\left[{ }^{3} \mathrm{H}\right]\right.$ glucose $)$.

Statistical methods. Results in the text, tables and figures are expressed as the mean \pm SEM. Student's $t$ test was performed for paired and unpaired data after logarithmic transformation. Correlation analysis was undertaken using the Spearman rank correlation coefficient.

\section{Results}

In all four groups an isotopic plateau was reached during the last $30 \mathrm{~min}$ of the equilibration period (Fig. 2). The mean coefficient of variation (CV) was below $5.2 \%$ for both isotopes. Plasma glucose was also stabilized during this period (Fig. 3) with a $\mathrm{CV}$ below $1.8 \%$. This implies that steady state conditions prevailed for both labeled and unlabeled glucose at the end of the equilibration period.

Glucose, C-peptide, and insulin concentrations. As seen in Fig. 3 and in Table II, plasma glucose appeared to be higher in

\section{CONTROLS}

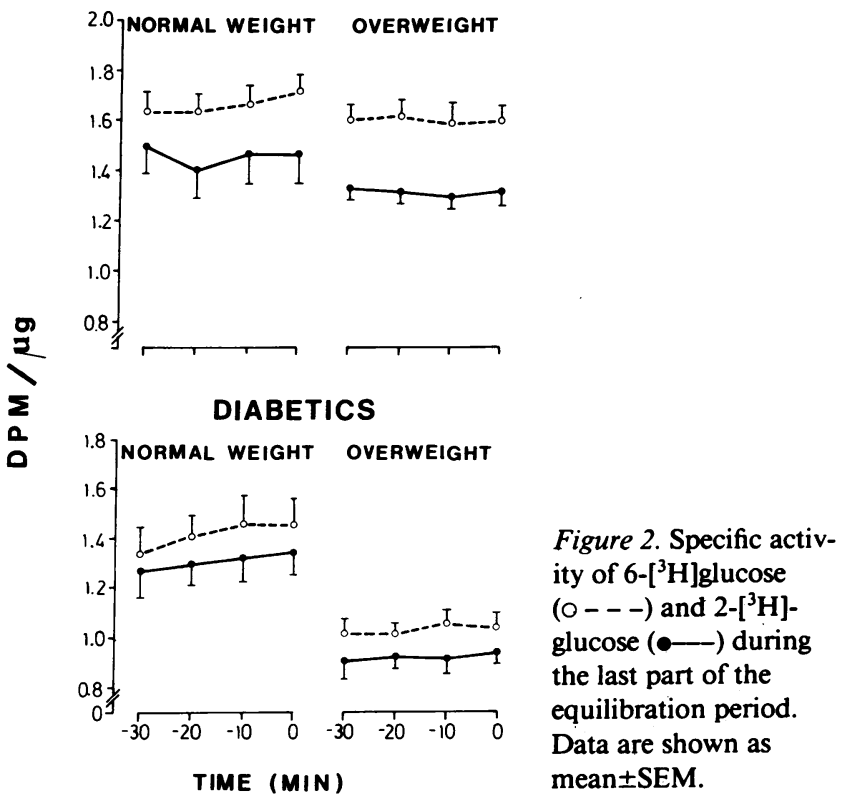




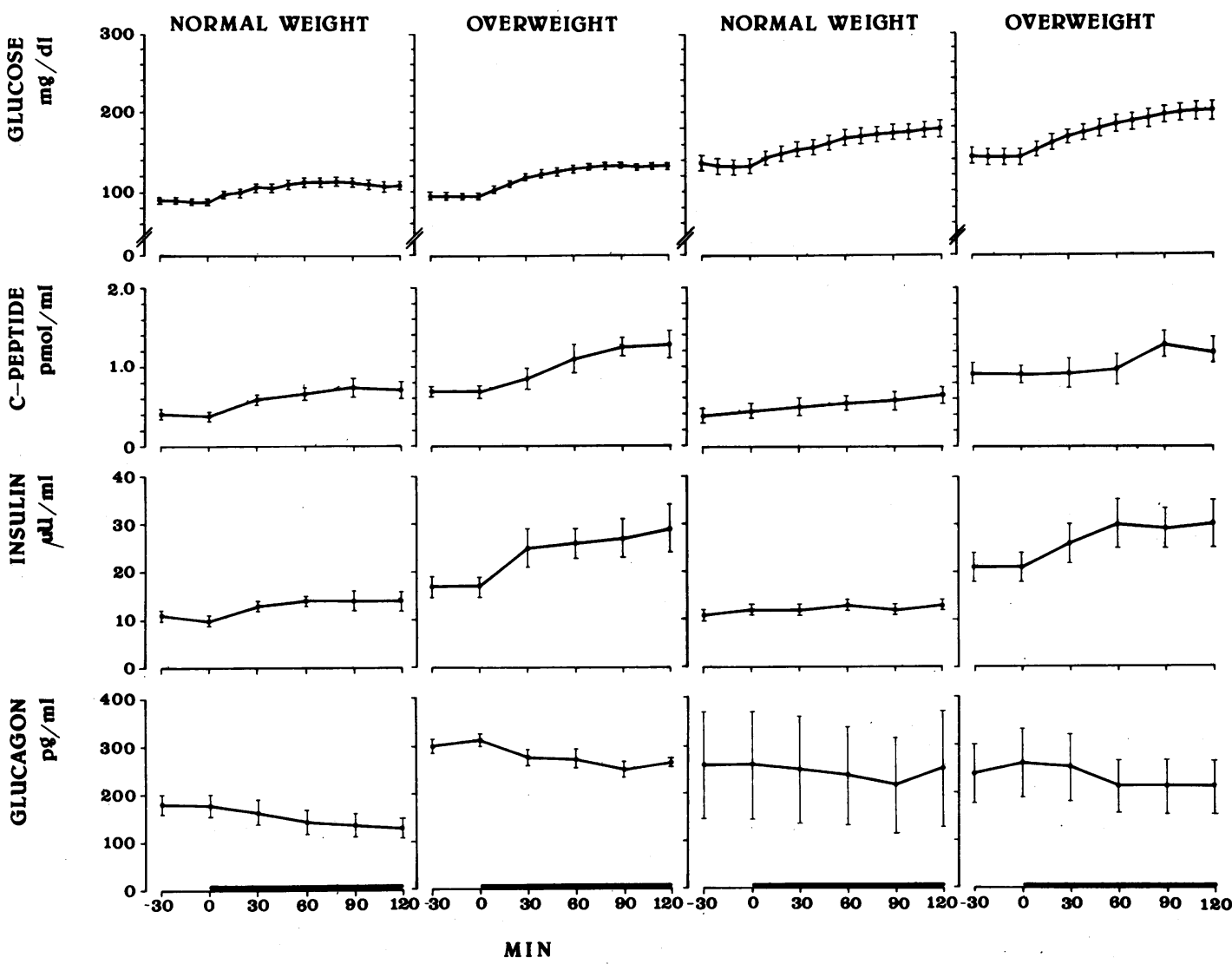

Figure 3. Effect of glucose infusion (0-120 min) on plasma concentrations of glucose, C-peptide, insulin and glucagon. Data are shown as mean \pm SEM.

overweight than in normal weight controls; this difference became highly significant during the glucose infusion period. In comparison with controls the diabetics had moderately but significantly elevated plasma glucose levels throughout the experiment. The basal and stimulated levels of plasma C-peptide and insulin were significantly higher in the overweight groups. Despite the more pronounced hyperglycemia during the glucose infusion both diabetic groups had similar plasma C-peptide and insulin levels as the corresponding controls. This indicates a decreased $\mathrm{C}$-peptide or insulin glucose ratio, an indi- cation of inappropriate insulin secretion. Plasma glucagon levels in the lean controls tended to be lower than in all other groups. There was no significant change in glucagon levels during glucose infusions.

Hepatic glucose production and irreversible glucose uptake. In the postabsorptive state HGP (measured with $6-\left[{ }^{3} \mathrm{H}\right]-$ glucose) was higher in normal weight than in overweight controls (Fig. 4, Table III). This difference, however, disappeared when HGP was expressed in relation to body surface area $\left(70 \pm 5\right.$ and $71 \pm 7 \mathrm{mg} / \mathrm{m}^{2}$ per min). Postabsorptive HGP was

Table II. Plasma Glucose, C-Peptide, and Insulin Patterns

\begin{tabular}{|c|c|c|c|c|c|c|}
\hline \multirow[b]{2}{*}{ Subjects } & \multicolumn{2}{|c|}{ Plasma glucose } & \multicolumn{2}{|c|}{ Plasma C-peptide } & \multicolumn{2}{|c|}{ Plasma insulin } \\
\hline & Basal state & Glucose infusion & Basal state & Glucose infusion & Basal state & Glucose infusion \\
\hline & \multicolumn{2}{|c|}{$m g / d l$} & \multicolumn{2}{|c|}{$\mathrm{pmol} / \mathrm{ml}$} & \multicolumn{2}{|c|}{$\mu U / m l$} \\
\hline \multicolumn{7}{|l|}{ Controls } \\
\hline Normal weight & $89 \pm 3$ & $110 \pm 5$ & $0.39 \pm 0.05$ & $0.73 \pm 0.10$ & $10 \pm 1$ & $14 \pm 2$ \\
\hline Overweight & $95 \pm 3$ & $133 \pm 3^{*}$ & $0.69 \pm 0.06^{*}$ & $1.29 \pm 0.15^{*}$ & $18 \pm 2^{\ddagger}$ & $29 \pm 4^{*}$ \\
\hline \multicolumn{7}{|l|}{ Diabetics } \\
\hline Normal weight & $133 \pm 9^{\S}$ & $176 \pm 9^{8}$ & $0.42 \pm 0.09$ & $0.60 \pm 0.10$ & $12 \pm 1$ & $13 \pm 1$ \\
\hline Overweight & $142 \pm 9^{8}$ & $196 \pm 11^{11}$ & $0.93 \pm 0.12^{*}$ & $1.25 \pm 0.12^{*}$ & $21 \pm 3^{\ddagger}$ & $30 \pm 4^{*}$ \\
\hline
\end{tabular}

${ }^{*} P<0.01,{ }^{\ddagger} P<0.05$, normal weight vs. overweight subjects. ${ }^{\S} P<0.001$, " $P<0.01$ diabetics vs. weight-matched controls. 


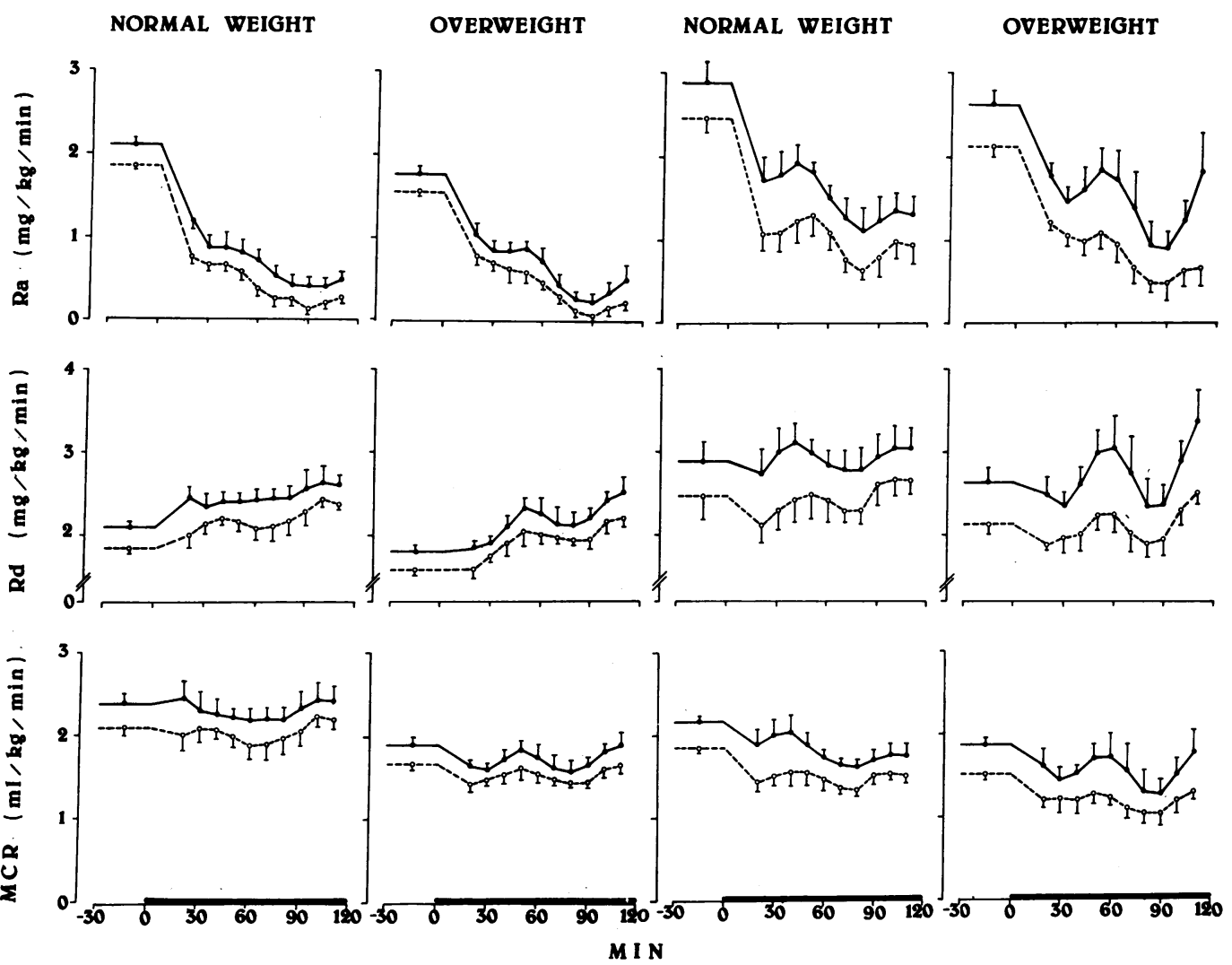

Figure 4. Effect of glucose infusion (0-120 min) on $R_{\mathrm{a}}$ and $R_{\mathrm{d}}$ as well as on MCR of glucose. Data are shown as mean $\pm \mathrm{SEM}$ for 6-[ $\left.{ }^{3} \mathrm{H}\right] \mathrm{glucose}$ $(0---)$ and $2-\left[{ }^{3} \mathrm{H}\right] \mathrm{glucose}(\bullet-)$.

higher in diabetics than in controls irrespective of body weight (33 and 35\%, respectively) (Fig. 5 A, Table III).

The glucose infusion caused a prompt suppression of HGP in all groups (Fig. 4, Table III). The degree of maximum suppression was less pronounced in diabetics either with normal weight (64 $\pm 7 \%, P<0.001)$ or overweight $(72 \pm 7 \%, P<0.005)$, than in the corresponding controls $(90 \pm 7$ and $91 \pm 4 \%$, respectively). This resulted in marked differences between lean (450\%) and obese (370\%) diabetics and the respective controls (Fig. 5 B).
In the postabsorptive state, irreversible glucose uptake equals glucose production (glucose turnover). This was higher in diabetics than in controls (Fig. 4, Table IV). The glucose infusion caused an increase in $R_{d}$ in the controls $(P<0.01)$ but had no effect in either lean or overweight diabetics. A very minor increase in $\boldsymbol{R}_{\mathrm{d}}$ was observed in normal weight diabetics only at the end of the experiment $(P<0.025)$.

$M C R$. In the postabsorptive state MCR was lower in overweight than in normal weight groups (Fig. 4, Table V). MCR was lower in lean diabetics than in the controls while no signif-

Table III. $R_{a}(\mathrm{mg} / \mathrm{kg}$ per min) in Controls and Diabetics

\begin{tabular}{|c|c|c|c|c|c|}
\hline \multirow[b]{2}{*}{ Subjects } & \multirow[b]{2}{*}{ Basal state } & \multicolumn{2}{|c|}{ Glucose infusion } & \multicolumn{2}{|c|}{ Glucose infusion } \\
\hline & & $20-110 \mathrm{~min}$ & $P$ vs. basal state & $90-110 \mathrm{~min}$ & $P$ vs. basal state \\
\hline \multicolumn{6}{|c|}{$\mathrm{mg} / \mathrm{kg} / \mathrm{min}$} \\
\hline \multicolumn{6}{|l|}{ Controls } \\
\hline Normal weight & $1.85 \pm 0.03$ & $0.40 \pm 0.04$ & $P<0.001$ & $0.20 \pm 0.04$ & $P<0.001$ \\
\hline Overweight & $1.59 \pm 0.06^{*}$ & $0.41 \pm 0.04$ & $P<0.001$ & $0.16 \pm 0.06$ & $P<0.001$ \\
\hline \multicolumn{6}{|l|}{ Diabetics } \\
\hline Normal weight & $2.47 \pm 0.18^{\ddagger}$ & $0.99 \pm 0.13^{8}$ & $P<0.001$ & $0.91 \pm 0.19^{\ddagger}$ & $P<0.001$ \\
\hline Overweight & $2.14 \pm 0.12^{\ddagger}$ & $0.81 \pm 0.05^{\S}$ & $P<0.001$ & $0.59 \pm 0.13^{\prime \prime}$ & $P<0.001$ \\
\hline
\end{tabular}

${ }^{*} P<0.01$ normal weight vs. overweight subjects. $" P<0.05,{ }^{\ddagger} P<0.01$, and ${ }^{8} P<0.001$ diabetics vs. weight-matched controls. During the glucose infusion $R_{a}$ was averaged between 20 and $110 \mathrm{~min}$ as well as between 90 and $110 \mathrm{~min}$. Data presented as mean $\pm \mathrm{SE}$. 
A. POSTABSORPTIVE STATE

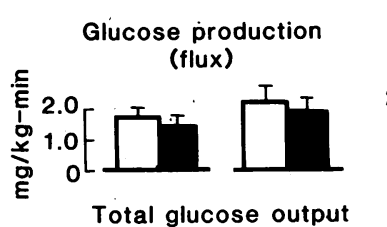

(glucose-6-phosphatase)
GLUCOSE INFUSION

Glucose production

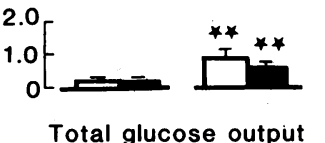

(glucose-6-phosphatase)

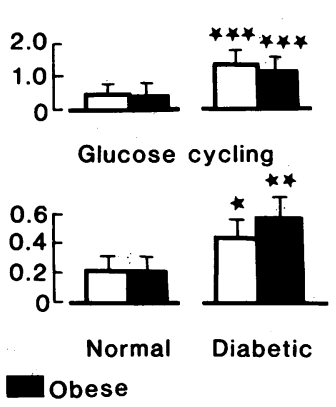

Figure 5 . Glucose turnover and cycling $(\mathrm{mg} / \mathrm{kg}$ per $\mathrm{min}$ ) in postabsorptive state $(A)$, and during 90-110 min of glucose infusion $(B)$. Data are shown as mean \pm SEM. ${ }^{*} P<0.05,{ }^{* *} P<0.01,{ }^{* * *} P<0.001$ diabetic vs. weight-matched controls. Total glucose output was suppressed during glucose infusion in normal and obese controls and diabetics $(P<0.001)$. Glucose cycling was significant in all cases $(P$ $<0.01)$.

icant difference was found between the two obese groups. During the glucose infusion MCR decreased in the obese $(P$ $<0.005)$ and in the lean diabetics $(P<0.001)$. There was no change in normal weight controls.

Total glucose output and glucose cycle. Under postabsorptive conditions (Figs. 4 and $5 A$ ) HTGO (measured with 2$\left[{ }^{3} \mathrm{H}\right]$ glucose) was higher than hepatic glucose production (measured with 6- $\left[{ }^{3} \mathrm{H}\right]$ glucose) in all groups of subjects, resulting in significant GC activity $(P<0.05)$. The activity of GC was significantly higher in the lean $(72 \%)$ and obese $(130 \%)$ diabetic groups than in the respective control groups. When the data of normal weight and obese control subjects were pooled together and compared to all diabetic subjects, the difference in GC was highly significant $(0.46 \pm 0.05$ and $0.24 \pm 0.04, P<0.005)$. In the combined diabetic groups, GC was positively correlated with fasting plasma glucose levels $(r$

$=0.59, P<0.05)$. Within the control and diabetic groups GC was not correlated to the body weight.

Glucose infusion did not change GC in any of the four studied groups, so that on the average, GC in the diabetics continued to be about 100\% higher than in controls (Figs. 4 and $5 B$ ). In contrast, this infusion suppressed apparent glucose-6-phosphatase activity much less in the diabetics than in the controls, resulting in marked enhancement in HTGO in the lean $(330 \%)$ and the obese $(400 \%)$ subjects (Fig. 5 B).

\section{Discussion}

In this study we demonstrate that in the postabsorptive state $0.43 \mathrm{mg} / \mathrm{kg}$ per min of glucose is turned through the $\mathrm{GC}$ in normal weight patients with type II diabetes while in matched healthy subjects GC activity amounted to about $0.25 \mathrm{mg} / \mathrm{kg}$ per min $(P<0.01)$. Obesity had no effect on GC in healthy and diabetic subjects. We presently calculated $G C$ as the difference in turnover rates between $2-\left[{ }^{3} \mathrm{H}\right]$ and $6-\left[{ }^{3} \mathrm{H}\right]$ glucose. This approach is based on two assumptions: $(a) 6-\left[{ }^{3} \mathrm{H}\right]$ glucose provides an appropriate measure of hepatic glucose production, and $(b)$ there is no tritium retention in C-2 of glucose-6phosphate. With respect to the first assumption, tritium from $6-\left[{ }^{3} \mathrm{H}\right]$ glucose is retained through the whole glycolytic process (24) and is lost to a large extent by carboxylation-decarboxylation reactions between pyruvate and dicarboxylic acids as well as by the action of glutamate-pyruvate transaminase (25). When the incorporation of tritium from $3-\left[{ }^{3} \mathrm{H}\right]$ lactate into glucose in hamster hepatocytes (26) and in fasting rats was measured (27) only $\sim 10 \%$ of the administered activity was recovered in glucose. This implies that even though some tritium from $6-\left[{ }^{3} \mathrm{H}\right]$ glucose can recycle it seems nevertheless that this tracer measures the rate of hepatic glucose production satisfactorily (28). The second assumption implies that tritium in $2-\left[{ }^{3} \mathrm{H}\right]$ glucose is completely lost in the hexose isomerase reaction. This, however, has not been ascertained. In vitro data suggest that a small amount of tritium is retained in hexose-6phosphates (29). If this occurs in vivo the activity of GC would be underestimated.

It appeared that GC was negligible in lean nondiabetic subjects when it was measured by comparing turnover rates of $2-\left[{ }^{3} \mathrm{H}\right]$ glucose and $3-\left[{ }^{3} \mathrm{H}\right]$ glucose (12). Also, GC in lean, mild diabetics measured previously by $3-\left[{ }^{3} \mathrm{H}\right]$ glucose $(12)$ was lower $(0.29 \mathrm{mg} / \mathrm{kg}$ per $\mathrm{min})$ than that measured by $6-\left[{ }^{3} \mathrm{H}\right] \mathrm{glucose}$ in the present experiments $(0.43 \mathrm{mg} / \mathrm{kg}$ per $\mathrm{min})$. We demonstrated that at least in some normal subjects, turnover mea-

Table IV. Rd ( $\mathrm{mg} / \mathrm{kg} / \mathrm{min})$ in Controls and Diabetics

\begin{tabular}{|c|c|c|c|c|c|}
\hline \multirow[b]{2}{*}{ Subjects } & \multirow[b]{2}{*}{ Basal state } & \multicolumn{2}{|c|}{ Glucose infusion } & \multicolumn{2}{|c|}{ Glucose infusion } \\
\hline & & $20-110 \mathrm{~min}$ & $P$ vs. basal state & $90-110 \mathrm{~min}$ & $P$ vs. basal state \\
\hline \multicolumn{6}{|l|}{ Controls } \\
\hline Normal weight & $1.85 \pm 0.03$ & $2.20 \pm 0.08$ & $P<0.001$ & $2.37 \pm 0.10$ & $P<0.001$ \\
\hline Overweight & $1.59 \pm 0.06^{*}$ & $1.95 \pm 0.07^{\ddagger}$ & $P<0.01$ & $2.09 \pm 0.10$ & $P<0.005$ \\
\hline \multicolumn{6}{|l|}{ Diabetics } \\
\hline Normal weight & $2.47 \pm 0.18^{\S}$ & $2.43 \pm 0.14$ & NS & $2.65 \pm 0.16$ & $P<0.025$ \\
\hline Overweight & $2.14 \pm 0.12^{\S}$ & $2.09 \pm 0.10$ & NS & $2.23 \pm 0.14$ & NS \\
\hline
\end{tabular}

\footnotetext{
${ }^{\ddagger} P<0.05$, and ${ }^{*} P<0.01$ normal weight vs. overweight subjects. ${ }^{\S} P<0.01$ diabetics vs. weight-matched controls. During the glucose infusion $R_{d}$ was averaged between 20 and $110 \mathrm{~min}$ as well as between 90 and $110 \mathrm{~min}$. Data are presented as mean \pm SEM.
} 


\begin{tabular}{|c|c|c|c|c|c|}
\hline \multirow[b]{2}{*}{ Subjects } & \multirow[b]{2}{*}{ Basal state } & \multicolumn{2}{|c|}{ Glucose infusion } & \multicolumn{2}{|c|}{ Glucose infusion } \\
\hline & & $20-110 \mathrm{~min}$ & $P$ vs. basal state & $90-110 \min$ & $P$ vs. basal state \\
\hline \multicolumn{6}{|l|}{ Controls } \\
\hline Normal weight & $2.11 \pm 0.09$ & $2.06 \pm 0.13$ & NS & $2.18 \pm 0.13$ & NS \\
\hline Overweight & $1.67 \pm 0.07^{*}$ & $1.54 \pm 0.05^{*}$ & $P=0.05$ & $1.58 \pm 0.09^{*}$ & NS \\
\hline \multicolumn{6}{|l|}{ Diabetics } \\
\hline Normal weight & $1.86 \pm 0.03^{\S}$ & $1.48 \pm 0.05^{\prime \prime}$ & $P<0.001$ & $1.52 \pm 0.03^{* *}$ & $P<0.001$ \\
\hline Overweight & $1.52 \pm 0.08^{*}$ & $1.18 \pm 0.11^{5,1}$ & $P<0.005$ & $1.17 \pm 0.12^{5,1}$ & $P<0.01$ \\
\hline
\end{tabular}

' $P<0.05$ and ${ }^{*} P<0.01$ normal weight vs. overweight subjects. ${ }^{\S} P<0.05$, "P<0.01, and ${ }^{* *} P<0.001$ diabetics vs. weight-matched controls. During the glucose infusion $R_{d}$ was averaged between 20 and $110 \mathrm{~min}$ as well as between 90 and $110 \mathrm{~min}$. Data are presented as mean $\pm S E M$.

sured with $3-\left[{ }^{3} \mathrm{H}\right]$ glucose is higher than turnover measured with $6-\left[{ }^{3} \mathrm{H}\right]$ glucose suggesting an active fructose-6-phosphate cycle (9). In addition, the dimedon technique used presently permitted us to determine simultaneously the turnovers of $2-\left[{ }^{3} \mathrm{H}\right]-$ and $6-\left[{ }^{3} \mathrm{H}\right]$ glucose whereas previously $2-\left[{ }^{3} \mathrm{H}\right]$ glucose and $3-\left[{ }^{3} \mathrm{H}\right]$ glucose were administered in separate experiments (12). The latter design may lead to intraindividual variations that would overshadow small differences in detritiation rates between the two isotopes. The rate of substrate cycling in general corresponds to the activity of a nonequilibrium enzyme that catalyzes a reaction opposite to the net metabolic flux (23). In the postabsorptive state the rate of glucose production reflects the difference between the activity of glucose-6-phosphatase and the activity of glucokinase. Phosphatase catalyzes the reaction that is in the same direction as the net flux while the kinase reflects GC. In the normal weight controls GC represents only $14 \%$ of the net flux (glucose production) or, in other words, the apparent activity of glucose-6-phosphatase is eight times larger than that of glucokinase. In lean and obese diabetic subjects, the relative increase in production was 33 and $44 \%$, respectively, while GC increased more (72 and $130 \%$, respectively). Since we have demonstrated a correlation between glucose concentration and $\mathrm{GC}$ it is feasible that, at least in part, the cycling increases with hyperglycemia because glucose is the substrate for glucokinase. The increase in GC in postabsorptive state could be seen as a protective mechanism that in diabetes limits the rate of glucose production, and therefore also the magnitude of hyperglycemia. It also appears that the measurement of glucose cycling is a more sensitive yardstick to detect defects in carbohydrate metabolism than measurements of net glucose fluxes. We have illustrated this point previously in normoglycemic acromegalic patients. Similar to the diabetics, the relative increase of GC was more marked than that of glucose production (13).

It is considered that substrate cycling has a number of important regulatory roles in glucose metabolism. Newsholme (23) has suggested that in the muscle the glycolytic pathway can be greatly accelerated when substrate cycling is already high. Such large and rapid acceleration of the glycolytic pathway is of particular importance during a short bout of intense, mainly anaerobic exercise. In contrast, in the liver the maximum increases of glucose production in nondiabetic and diabetic dogs are not in excess of three- to fivefold $(30,31)$, but the hepatic net flux changes its direction with the feeding-fasting cycles. In the liver glucose-6-phosphate is a branch point for several pathways with at least four outflows (glucose, fructose- 1,6-diphosphate, glycogen and the pentose cycle) and an equal number of inputs. The glucose cycle could be an important stop gap that can prevent inappropriate changes in fluxes, because in order to change the direction of the flux one needs either to induce a very large change in one enzyme or change the activities of the two enzymes in opposite directions. This implies a more complex control than simple changes in net fluxes that occur in near-equilibrium reactions.

When glucose is infused, the net flux is reversed from glucose production to net glucose influx. The enzyme that catalyzes the reaction that is opposite to the net flux is glucose-6phosphatase, which corresponds to total glucose output measured by $2-\left[{ }^{3} \mathrm{H}\right]$ glucose. Radziuk (32) suggested that the liver will take up $\sim 25 \%$ of the glucose presented. Therefore, during an infusion of $2 \mathrm{mg} / \mathrm{kg}$ per min the net uptake of glucose could amount to $0.5 \mathrm{mg} / \mathrm{kg}$ per min. This would mean that GC could amount to $40 \%$ of the net glucose flux. In general, glucose infusion decreased the activity of glucose-6-phosphatase, and it is debated whether this is a primary effect of hyperglycemia $(33,34)$. This mechanism facilitates the reversal of the metabolic flux. It is defective in diabetes where the activity of glucose-6-phosphatase is less suppressed than in the controls despite much higher glucose levels. Such residual high activity of the phosphatase could contribute to hyperglycemia during a glucose challenge. Thus, it appears that in the postabsorptive state, GC has a protective role against hyperglycemia, while postprandially, it could further aggravate postprandial hyperglycemia.

The mechanism of increased GC in mild type II diabetics is not clear. At the present time one cannot distinguish between the cause or the effect. For example, the increased activity of glucose-6-phosphatase both in the postabsorptive state and during glucose challenge could indirectly result from insulin resistance through an unknown chain of metabolic events. It is unlikely that it is related to hyperglycemia per se because this should reduce and not increase activity of this enzyme.

Apart from increased GC, our investigation revealed other metabolic derangements in normal weight diabetics. Although the subjects had only mild hyperglycemia (fasting values $133 \pm 9 \mathrm{mg} / \mathrm{dl}$ ) HGP was increased in the basal state and was not effectively suppressed during glucose administration despite marked hyperglycemia and a significant increase in Cpeptide levels. Using 3-[ $\left.{ }^{3} \mathrm{H}\right]$ glucose an increase in basal HGP was not demonstrated in patients with type II diabetes who had a mean fasting blood glucose of $117 \mathrm{mg} / \mathrm{dl}(35), 123 \mathrm{mg} / \mathrm{dl}$ (12), $129 \mathrm{mg} / \mathrm{dl} \mathrm{(36),} \mathrm{and} 149 \mathrm{mg} / \mathrm{dl}$ (37). It is possible that by 
using $3-\left[{ }^{3} \mathrm{H}\right]$ glucose a small but significant elevation of basal $R_{\mathrm{a}}$ in mild type II diabetes is overlooked. Also, during large glucose infusions (hyperinsulinemic euglycemic clamps), endogenous glucose production is underestimated $(38,39)$.

This study with $6-{ }^{3} \mathrm{H}$ tracer corroborates our previous observation with $3-\left[{ }^{3} \mathrm{H}\right]$ glucose that a glucose infusion suppresses HGP to a lesser degree in mild type II diabetics than in controls in spite of a more pronounced hyperglycemia $(12,36)$. With a sequential hyperinsulinemic euglycemic clamp technique (40-42) an impaired suppressibility of HGP was also found in subjects with impaired glucose tolerance and in type II diabetes. Such a difference could not be detected when insulin levels were clamped at $100 \mu \mathrm{U} / \mathrm{ml}$ (43). Peripheral insulin resistance was also revealed since MCR was lower and glucose infusion did not augment glucose uptake in lean diabetics in spite of hyperglycemia and significant C-peptide release. Indeed, insulin resistance is generally recognized as an important feature of the diabetic state $(44,45)$. During glucose infusion, plasma glucose increased more in obese than in the lean controls despite higher insulin levels. This indicates insulin resistance as also shown by the hyperinsulinemic euglycemic clamp (46). The significant drop in MCR shows that at least part of this insulin resistance is related to glucose uptake. The activity of GC in postabsorptive state and during glucose infusion was not affected by obesity. This implies that insulin resistance observed in the obese is not related to hepatic glucose uptake as assessed by measurements of the rate of glucose cycling. The postabsorptive ATP consumption accounted for by glucose cycling was $\sim 0.3 \mathrm{~mol} / 24 \mathrm{~h} \mathrm{(23)}$. This corresponds to a daily heat production of $\sim 5 \mathrm{kcal}$, an amount much too small to play any role in the pathogenesis of obesity. Obese diabetics had metabolic alterations very similar to lean diabetics. There was an increase in basal glucose production that was not adequately suppressed with hyperglycemia. Hence, hepatic and extrahepatic insulin resistance is pronounced in the obese diabetics more than in the obese controls.

An interesting question is whether oscillation in $R_{\mathrm{a}}$ and $R_{\mathrm{d}}$ are related to oscillations in insulin secretion (47). Infrequent and peripheral insulin measurements in our study cannot answer this question.

In conclusion, in mild lean and obese type II diabetics we have observed inappropriate insulin release and decreased insulin sensitivity. Manifestations of the overall insulin resistance relate to decreased metabolic clearance of glucose and inadequate increase of glucose uptake during glucose infusions. Hepatic insulin resistance is indicated because there is an increased postabsorptive glucose production and impaired suppression of glucose production during glucose infusion. Another marked hepatic abnormality noted was an increase in GC of 72 to $130 \%$ in the postabsorptive state. This increase in GC limits a further increase in glucose production and, therefore, in glycemia. During glucose infusion, glucose-6-phosphatase determines the rate of GC. In diabetes this activity is not adequately suppressed during glucose infusion and GC is actually threefold larger than in controls. This could contribute to postprandial hyperglycemia. It appears that GC, a potential stop gap in the control of changes from glucose production to uptake, represents a very sensitive probe to assess early diabetic metabolic disorders and is specific for metabolism in the liver.

\section{Acknowledgments}

We are grateful to Mr. A. Roovete, Ms. K. Waldelof, and Ms. E. Sandberg for excellent technical assistance. M. Vranic is grateful to Dr. E. Newsholme for the many invaluable discussions regarding metabolic control mechanisms (including those of substrate cycling) during a sabbatical leave at Oxford University as a visiting research fellow at Merton College. We are also indebted to Dr. B. Landau for many excellent suggestions during his sabbatical stay in Stockholm.

This work was supported by the Swedish Medical Research Council (grant 0034), the Nordic Insulin Foundation (Gentofte, Denmark), the Swedish Diabetic Association and the Medical Research Council of Canada (MT 2197).

\section{References}

1. Altszuler, N., A. Barkai, B. Gottlieb, and R. Steele. 1975. Glucose turnover values in the dog obtained with various species of labeled glucose. Am. J. Physiol. 229:1662-1667.

2. Issekutz, B. 1977. Studies on hepatic glucose cycles in normal and methylprednisoline-heated dogs. Metab. Clin. Exp. 26:157-170.

3. Vranic, M., H. L. A. Lickley, F. W. Kemmer, G. Perez, G. Hetenyi, T. W. Hatton, and N. Kovacevic. 1981. In Etiology and Pathogenesis of Insulin-Dependent Diabetes Mellitus. J. M. Martin, R. M. Ehrlich, and F. J. Holland, editors. Raven Press, New York. 153-178.

4. Anwer, M. S., T. W. Chapman, and R. Gronwall. 1976. Glucose utilization and recycling in ponies. Am. J. Physiol. 230:138-142.

5. Hue, L., and H. G. Hers. 1974. On the use of $(3 \mathrm{H}, 14 \mathrm{C})$ labelled glucose in the study of the so-called "futile cycles" in liver and muscle. Biochem. Biophys. Res. Commun. 58:532-539.

6. Dunn, A., J. Katz, S. Golden, and M. Chenoweth. 1976. Estimation of glucose turnover and recycling in rabbits using various $\left({ }^{3} \mathrm{H}\right.$, ${ }^{14}$ C) labels. Am. J. Physiol. 230:1159-1162.

7. Brady, L. J., D. R. Rosmos and G. A. Leveille. 1977. Glucose turnover in the young chicken (Gallus domesticus) using variously labeled $\left({ }^{3} \mathrm{H},{ }^{14} \mathrm{C}\right)$ glucose tracers. Comp. Biochem. Physiol. 56B:421425.

8. Okajima, F., and M. Ui. 1979. Metabolism of glucose in hyperand hypothyroid rats in vivo. Glucose turnover values and futile-cycle activities obtained with ${ }^{14} \mathrm{C}$ and ${ }^{3} \mathrm{H}$ labelled glucose. Biochem. $J$. 182:565-575.

9. Karlander, S., A. Roovete, M. Vranic, and S. Efendic. 1986. Glucose and fructose 6-phosphate cycle in man. Am. J. Physiol. (Endocrinol. Metab. 14) 251:E530-E536.

10. Shulman, G. I. P., W. Ladenson, M. M. Wolfe, E. C. Ridgway, and R. R. Wolfe. 1985. Substrate cycling between gluconeogenesis and glycolysis in euthyroid, hypothyroid and hyperthyroid man. J. Clin. Invest. 76:757-764.

11. Lickley, H. L. A., F. W. Kemmer, K. M. A. El Tayeb, and M. Vranic. Importance of glucagon in the control of futile cycling as studied in alloxan-diabetic dogs. Diabetologia. 30:175-182, 1987.

12. Efendic, S., A. Wajngot, and M. Vranic. 1985. Increased activity of glucose cycle in the liver: early characteristic of Type II diabetes. Proc. Natl. Acad. Sci. USA. 82:2965-2969.

13. Karlander, S., M. Vranic, and S. Efendic. 1986. Increased glucose turnover and glucose cycling in acromegalic patients with normal glucose tolerance. Diabetologia. 29:778-783.

14. Efendic, S., A. Wajngot, and E. Cerasi. 1980. Insulin release, insulin sensitivity and glucose intolerance. Proc. Natl. Acad. Sci. USA. 77:7425-7429.

15. Hugget, A. S. G., and D. A. Nixon. 1957. Use of glucose oxidase, peroxidase and O-dianisidene in determination of blood and urinary glucose. Lancet. ii:368-370.

16. Herbert, V., K. S. Lau, C. W. Gottlieb, and S. J. Bleicher. 1965. 
Coated charcoal immunoassay of insulin. J. Clin. Endocrinol. Metab. 25:1375-1384.

17. Faloona, G. R., and R. H. Unger. 1974. Glucagon radioimmunoassay In Methods of Hormone Radioimmunoassay. B. M. Jaffe, and H. R. Behrman, editors. Academic Press, New York. 317-330.

18. Dunn, D. F., B. Friedman, A. R. Maass, G. A. Reich, and S. Weinhouse. 1957. Effects of insulin on blood glucose entry and removal in normal dogs. J. Biol. Chem. 225:225-237.

19. DeBodo, R. C., R. Steele, N. Altszuler, A. Dunn, and J. S. Bishop. 1963. O the hormonal regulation of carbohydrate metabolism: studies with C14 glucose. Recent. Prog. Horm. Res. 19:445-488.

20. Cowan, H. S., and G. Hetenyi, Jr. 1971. Glucoregulatory response in normal and diabetic dogs recorded by a new tracer method. Metab. Clin. Exp. 20:360-372.

21. Radziuk, J., K. H. Norwich, and M. Vranic. 1978. Experimental validation of measurements of glucose turnover in non-steady state. Am. J. Physiol. (Endocrinol. Metab.) 234:E84-E93.

22. Cherrington, A. D., and M. Vranic. 1973. Effect of arginine on glucose turnover and plasma free fatty acids in normal dogs. Diabetes. 22:537-543.

23. Newsholme, E. A., and B. Crabtree. 1976. Substrate cycles in metabolic regulation and in heat generation. Biochem. Soc. Symp. 41:61-109.

24. Hue, L. 1981. The role of futile cycles in the regulation of carbohydrate metabolism in the liver. Adv. Enzymol. 52:247-331.

25. Katz, J., and R. Rognstad. 1976. Futile cycles in the metabolism of glucose. Curr. Top. Cell Regul. 10:237-289.

26. Rognstad, R., and P. Wals. 1976. The metabolism of $\mathrm{L}-\left(3-{ }^{3} \mathrm{H}\right)$ lactate by isolated hamster liver cells. Biochem. Biophys. Acta. 437:16-21.

27. Okajima, F., M. Chenoweth, R. Rognstad, A. Dunn, and J. Katz. 1981. Metabolism of ${ }^{3} \mathrm{H}$ and ${ }^{14} \mathrm{C}$ labelled lactate in starved rats. Biochem. J. 194:525-540.

28. Katz, J. 1974. Use of isotopes for the study of glucose metabolism in vivo. In Techniques in Metabolic Research. C. Pogsar, editor. Vol. 2. Elsevier, Amsterdam. B1207-B1222.

29. Katz, J., P. A. Wals, and R. Rognstad. 1978. Glucose phosphorylation, glucose 6-phosphatase and recycling in rat hepatocytes. J. Biol. Chem. 253:4530-4536.

30. Perez, G., F. W. Kemmer, H. L. A. Lickley, and M. Vranic. 1981. Importance of glucagon in mediating epinephrine-induced hyperglycemia in alloxan-diabetic dogs. Am. J. Physiol. (Endocrinol. Metab. 4) 241:E328-E335.

31. Wasserman, D. H., H. L. A. Lickley, and M. Vranic. 1984. Interactions between glucagn and other counterregulatory hormones during normoglycemic and hypoglycemic exercise in dogs. J. Clin. Invest. 74:1404-1413.

32. Radziuk, J. 1987. Tracer methods and the metabolic disposal of a carbohydrate load in man. In Diabetes/Metabolism Reviews. R. DeFronzo, editor. Vol. 3. John Wiley \& Sons. Inc., New York.
33. Young, J. H., M. S. Youn, and R. N. Bergman. 1986. Synergism of glucose and fructose in net glycogen synthesis in perfused rat liver. J. Biol. Chem. 261:1-10.

34. Newgard, C. B., D. W. Foster, and J. D. McGarry. 1984. Evidence for suppression of hepatic glucose 6-phosphatase with carbohydrate feeding. Diabetes. 33:192-195.

35. De Fronzo, R. A., D. Deibert, R. Hendler, P. Felig, and V. Soman. 1979. Insulin sensitivity and insulin binding to monocytes in maturity-onset dibetes. J. Clin. Invest. 63:939-946.

36. Wajngot, A., A. Roovete, M. Vranic, R. Luft, and S. Efendic. 1982. Insulin resistance and decreased insulin response to glucose in lean Type II diabetics. Proc. Natl. Acad. Sci. USA. 79:4432-4436.

37. De Fronzo, R. A., D. Simonson, and E. Ferrannini. 1982. Hepatic and peripheral insulin resistance: a common feature of Type 2 (noninsulin-dependent) and Type 1 (insulin-dependent) diabetes mellitus. Diabetologia. 23:313-319.

38. Bell, P., R. G. Firth, and R. A. Rizza. 1986. Assessment of insulin action $n$ insulin-dependent diabetes mellitus using $\left[6-{ }^{14} \mathrm{C}\right]-$ glucose, $\left[3-{ }^{3} \mathrm{H}\right]$ glucose and $\left[2-{ }^{3} \mathrm{H}\right]$ glucose. Difference in apparent pattern of insulin resistance depending on the isotope used. J. Clin. Invest. 78:1479-1486.

39. Finegood, D. T., R. N. Bergman, and M. Vranic. 1987. Estimation of endogenous glucose production during hyperinsulinemic euglycemic glucose clamps: comparison of unlabeled and labeled exogenous glucose infusates. Diabetes. 36:914-924.

40. Kolterman, O. G., R. S. Gray, J. Griffin, P. Burstein, J. Insel, J. A. Scarlett, and J. M. Olefski. 1981. Receptor and postreceptor defects contribute to the insulin resistance in noninsulin-dependent diabetes mellitus. J. Clin. Invest. 68:957-969.

41. Nankervis, A., J. Proie Ho, and P. Aitken. 1982. Differential effects of insulin therapy on hepatic and peripheral insulin sensitivity in type 2 (non insulin-dependent) diabetes. Diabetologia. 23:320-325.

42. Firth, R. G., P. M. Bell, and R. A. Rizza. 1986. Effect of tolazamide and exogenous insulin action in patients with non insulindependent diabetes mellitus. $N$. Engl. J. Med. 314:1280-1286.

43. De Fronzo, R. A., R. Gunnarsson, O. Bjorkman, M. Olson, and J. Wahren. 1985. Effects of insulin in peripheral and splanchnic glucose metabolism in noninsulin-dependent (type II) diabetes mellitus). J. Clin. Invest. 76:149-155.

44. Bergman, R. N., D. T. Finegood, and M. Adex. 1985. Assessment of insulin sensitivity in vivo. Endocrine Rev. 6:45-86.

45. Vranic, M., S. Morita, and G. Steiner. 1980. Insulin resistance in obesity analyzed by response of glucose kinetics to glucagon infusion. Diabetes. 29:169-176.

46. Kolterman, O. G., J. Insel, M. Sackow, and J. M. Olefsky. 1980. Mechanisms of insulin resistance in human obesity. Evidence for receptor and postreceptor defects. J. Clin. Invest. 65:1272-1284.

47. Marsh, B. D., D. J. Marsh, and R. N. Bergman. 1986. Oscillations enhance the efficiency and stability of glucose disposal. Am. J. Physiol. (Endocrinol. Metab. 13) 250:E576-E582. 